\title{
Preferred Features of a Fluorine-19 MRI Probe for Amyloid Detection in the Brain
}

\author{
Daijiro Yanagisawa ${ }^{\mathrm{a}}$, Hiroyasu Taguchi ${ }^{\mathrm{a}}$, Nor Faeizah Ibrahim ${ }^{\mathrm{a}}$, Shigehiro Morikawa ${ }^{\mathrm{b}}$, \\ Akihiko Shiino $^{\mathrm{b}}$, Toshiro Inubushib ${ }^{\mathrm{b}}, \mathrm{Koichi}_{\mathrm{Hirao}}{ }^{\mathrm{c}}$, Nobuaki Shirai ${ }^{\mathrm{c}}$, Takayuki Sogabe ${ }^{\mathrm{d}}$ \\ and Ikuo Tooyama ${ }^{\mathrm{a}, *}$ \\ ${ }^{\mathrm{a}}$ Molecular Neuroscience Research Center, Shiga University of Medical Science, Seta Tsukinowa-cho, Otsu, Japan \\ ${ }^{\mathrm{b}}$ Biomedical MR Science Center, Shiga University of Medical Science, Seta Tsukinowa-cho, Otsu, Japan \\ ${ }^{\mathrm{c}}$ Northeastern Industrial Research Center of Shiga Prefecture, Nagahama, Japan \\ d Otsuka Pharmaceutical Co., Ltd, Kawauchi-cho, Japan
}

Handling Associate Editor: Shun Shimohama

Accepted 2 October 2013

\begin{abstract}
Fluorine-19 magnetic resonance imaging $\left({ }^{19} \mathrm{~F}\right.$ MRI) could be a promising approach for imaging amyloid deposition in the brain. However, the required features of a ${ }^{19} \mathrm{~F}$ MRI probe for amyloid detection remain unclear. In the present study, we investigated a series of compounds as potent ${ }^{19} \mathrm{~F}$ probes that could prevent the reduction in MR signal when bound to amyloid plaques in the brain. Each compound consists of styrylbenzoxazole as a core structure linked by a different length of polyethylene glycol (PEG) chain to one of three types of fluorine-labeled group: a trifluoroethoxy group, a hexafluoroisopropoxy

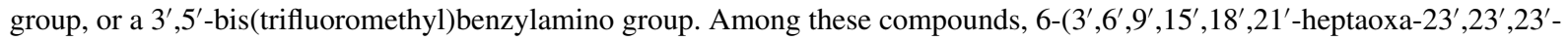
trifluorotricosanyloxy)-2-(4'-dimethylaminostyryl)benzoxazole [compound $3 \mathrm{~b}(\mathrm{~m}=6)$ ], which has a trifluoroethoxy group with seven ethylene glycol groups in the PEG chain, showed significant ${ }^{19} \mathrm{~F}$ MR signals in the brains of AßPPswe/PS1dE9 doubletransgenic mice, but not wild-type mice. This suggested that compound $3 \mathrm{~b}(\mathrm{~m}=6)$ could be a useful ${ }^{19} \mathrm{~F}$ MRI probe for amyloid detection. Furthermore, this study identified the most effective length of PEG chain between the fluorine-labeled group and the core structure to ensure a strong MR signal when the probe is bound to amyloid plaques.
\end{abstract}

Keywords: Alzheimer's disease, amyloid deposition, amyloid imaging, fluorine-19 MRI, magnetic resonance imaging

\section{INTRODUCTION}

Alzheimer's disease $(\mathrm{AD})$ is characterized by a progression from episodic memory problems to a slow global decline in cognitive function [1,2]. The pathological features of $\mathrm{AD}$ include the formation of senile plaques composed of extracellular deposits of

\footnotetext{
${ }^{*}$ Correspondence to: Ikuo Tooyama, M.D., Ph.D., Molecular Neuroscience Research Center, Shiga University of Medical Science, Seta Tsukinowa-cho, Otsu 520-2192, Japan. Tel.: +81 77 548 2330; Fax: +81 77548 2331; E-mail: kinchan@belle.shigamed.ac.jp.
}

amyloid- $\beta(A \beta)$ and neurofibrillary tangles formed by the intracellular accumulation of abnormally hyperphosphorylated tau. Recent evidence concerning the progression of $\mathrm{AD}$ strongly supports the amyloid cascade hypothesis in which a pathological change of $A \beta$ in the brain is an initiating event [3,4]. Deposition of $A \beta$ occurs many years before clinical symptoms appear. After a lag period, neurofibrillary tangle formation and neuronal loss become abnormal, leading to cognitive impairment. Accordingly, estimating the level of $\mathrm{A} \beta$ deposition in the brain would be informative for early diagnosis of $\mathrm{AD}$ and for evaluating $\mathrm{AD}$ progression. Furthermore, such a measure could help to 
find asymptomatic individuals at the preclinical stage of $\mathrm{AD}$ [5].

Noninvasive imaging methods to visualize $A \beta$ deposition in the brain, such as positron emission tomography (PET), have recently attracted much attention. Magnetic resonance imaging (MRI) is another promising modality for amyloid imaging, and several novel contrast agents and pulse sequences for the detection of amyloid deposition using MRI have been reported [6-17]. Indeed, we have developed novel fluorine-19 $\left({ }^{19} \mathrm{~F}\right)$-labeled contrast agents for the detection of amyloid deposition using ${ }^{19} \mathrm{~F}$ MRI [18-20]. The advantages of ${ }^{19} \mathrm{~F}$ MRI are as follows: MR sensitivity of ${ }^{19} \mathrm{~F}$ is relatively high compared to the sensitivity of various nuclei other than ${ }^{1} \mathrm{H}\left({ }^{1} \mathrm{H}, 100 \% ;{ }^{19} \mathrm{~F}, 83 \% ;{ }^{31} \mathrm{P}, 6.6 \%\right.$; ${ }^{13} \mathrm{C}, 1.6 \%$ ); no ${ }^{19} \mathrm{~F}$ atoms exist in biological tissues, thus producing low endogenous background noise; and, the ${ }^{19} \mathrm{~F}$ atom is a non-radioactive isotope, with $100 \%$ natural abundance. Accordingly, ${ }^{19} \mathrm{~F}$ MRI would be a highly sensitive, easily available, low-background, and cost-effective approach for detecting $A \beta$ deposition once a suitable high-quality probe is developed. However, the preferred features of a probe used for amyloid imaging with ${ }^{19} \mathrm{~F}$ MRI are still unclear. Our previous study demonstrated that highly hydrophobic probes might be trapped by the lipid components of the brain such as myelin, thus inhibiting molecule mobility, causing shortening of $\mathrm{T}_{2}$ and broadening of the MR signal, and in turn a reduction in MR signal [18]. This reduction in MR signal is induced when the probe binds to amyloid plaques in the brain $[18,20]$. Accordingly, a method to regulate the hydrophilicity/hydrophobicity of the probe and thus avoid the reduction in MR signal when the probe is bound to amyloid plaques is a key factor in the development of a high-quality ${ }^{19} \mathrm{~F}$ MRI probe for amyloid imaging.

In the present study we investigated a series of compounds as potent ${ }^{19} \mathrm{~F}$ probes that may generate strong MR signals when bound to amyloid plaques in the brain. The probes consist of a core structure linked to a different fluorine-labeled group by a specific length of polyethylene glycol (PEG) chain (from 2 to 12 ethylene glycol units). The fluorine labels examined belong to one of three types of trifluoromethyl groups: a single trifluoromethyl group (3b, 5b), two equivalent trifluoromethyl groups attached to an aliphatic carbon atom $(3 \mathrm{c}, 5 \mathrm{c})$, and two equivalent trifluoromethyl groups attached to an aromatic ring carbon $(3 \mathrm{a}, 5 \mathrm{a})$. The aim of the study was to determine the optimum length of PEG chain to link with the appropriate fluorine-labeled group to generate a probe capable of detecting amyloid deposition in the brain with ${ }^{19} \mathrm{~F}$ MRI.

\section{MATERIALS AND METHODS}

\section{Synthesis}

We synthesized a series of compounds as potent ${ }^{19} \mathrm{~F}$ MRI probes. They were fluorescent chemicals, and each compound consisted of styrylbenzoxazole as a core structure linked to a different fluorine-labeled group by a different length of PEG chain. The synthetic pathways are depicted in the Supplementary Materials and Methods, and Supplementary Table 1. In brief, styrylbenzoxazoles with fluorine substituents (compounds 3 and 5) were prepared according to a previously reported procedure [18]. Thus, compound 2 probes $(\mathrm{m}=2 \sim 6)$ were made from 6-hydroxy-2- $\left(4^{\prime}-\right.$ dimethylaminostyryl)benzoxazole (compound 1) by a Mitsunobu reaction. The preparation procedure for compound 3 is summarized in Scheme 1A. Reaction of compound 2 with benzylamine derivatives in dimethyl sulfoxide produced the benzylamino derivative $3 \mathrm{a}$ with fluorine substituents. Compounds $3 \mathrm{~b}$ to $3 \mathrm{~d}$ were made by substitution of the tosyloxy group with alkoxides prepared from the appropriate alcohol and sodium hydride in tetrahydrofuran or N,N-dimethylformamide. The fluorine derivatives with longer PEG chains (compound 5, $\mathrm{m}+\mathrm{n}=7 \sim 12$ ) were prepared from compound $3 \mathrm{~d}$ as shown in Scheme 1B. The deprotection of the tetrahydropyranyl group of compound $3 \mathrm{~d}$ with hydrochloric acid in ethanol gave the corresponding alcohols, which were readily tosylated to produce compound 4 . For compounds with a benzylamine derivative or alkoxide, a substitution reaction of the tosyloxy group was performed in a similar manner to that for compound 3 . The values of molecular mass and $\mathrm{C} \log \mathrm{P}$ of the compounds synthesized in the present study are listed in Table 1.

Table 1

Molecular masses and $\mathrm{C} \log \mathrm{P}$ values for the synthesized compounds

\begin{tabular}{lcc}
\hline Name & Molecular mass & ClogP \\
\hline $3 a(m=2)$ & 637.61 & 6.77 \\
$3 a(m=3)$ & 681.66 & 6.61 \\
$3 a(m=4)$ & 725.72 & 6.46 \\
$3 a(m=5)$ & 769.77 & 6.30 \\
$3 b(m=2)$ & 494.50 & 4.39 \\
$3 b(m=4)$ & 582.61 & 4.08 \\
$3 b(m=5)$ & 626.66 & 3.93 \\
$3 b(m=6)$ & 670.71 & 3.77 \\
$5 b(m+n=7)$ & 714.77 & 3.62 \\
$5 b(m+n=8)$ & 758.82 & 3.46 \\
$5 b(m+n=10)$ & 846.92 & 3.15 \\
$5 b(m+n=12)$ & 935.03 & 2.84 \\
$3 c(m=2)$ & 518.45 & 5.51 \\
$3 c(m=6)$ & 694.66 & 4.89 \\
$5 c(m+n=8)$ & 782.76 & 4.58
\end{tabular}


A

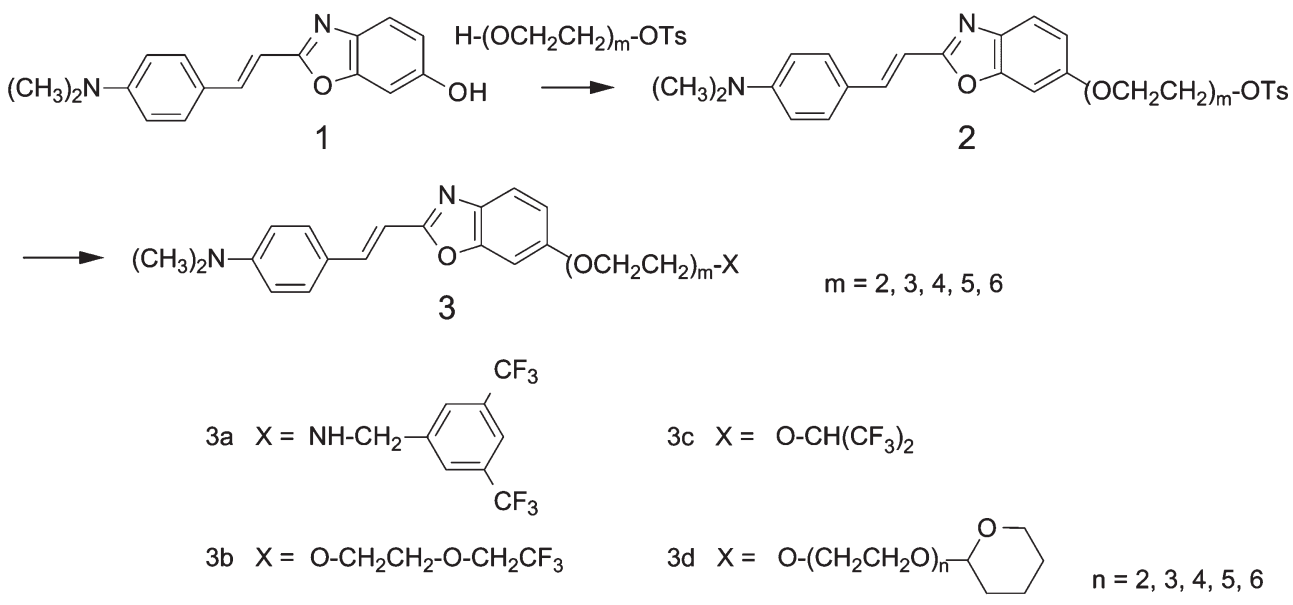

B

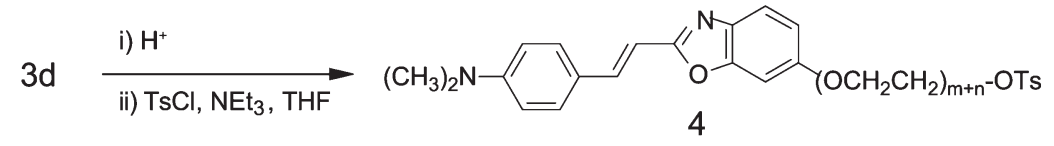<smiles>[X]CCCOc1ccc2nc(C=Cc3ccc(N(C)C)cc3)oc2c1</smiles>

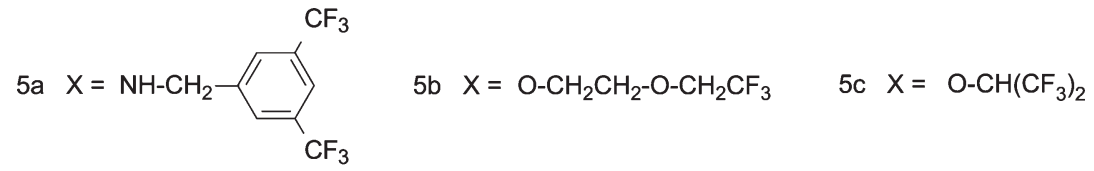

C Compound $3 \mathrm{~b}(\mathrm{~m}=6)$

Scheme 1. Synthesis and structures of styrylbenzoxazole derivatives. The numbers ' $m$ ' and ' $m+n$ ' express the length of the polyethylene glycol (PEG) chain. The compounds bearing shorter chains $(\mathrm{m} \leq 6)$ belong to 'compound 3' and those bearing longer ones $(\mathrm{m}+\mathrm{n} \geq 7)$ belong to 'compound 5'. The groups ' $a$ ', ' $b$ ' and 'c' express the type of trifluoromethyl groups attached to the PEG chain. Compounds $3 a$ and 5a contain a 3,5-bis(trifluoromethyl)benzylamino group, compounds $3 \mathrm{~b}$ and $5 \mathrm{~b}$ contain a 2,2,2-trifluoroethoxy group, and compounds $3 \mathrm{c}$ and $5 \mathrm{c}$ contain a hexafluoroisopropoxy group.

\section{Animals}

A $\beta P$ swe/PS1dE9 double-transgenic (AßPP/PS1) mice with a C57BL/6 background were obtained from Jackson Laboratory (Bar Harbor, ME). The A $\beta P P / P S 1$ mice express a chimeric mouse/human amyloid- $\beta$ protein precursor (A $\beta P P$ ) with mutations K594N and M595L linked to Swedish familial AD (Mo/HuAßPP695swe), and human presenilin 1 (PS1) carrying the exon-9-deleted variant associated with familial AD (PS1dE9) [21]. Two transgenes are inserted at a single locus, and each is controlled by an independent mouse prion promoter element, directing transgene expression predominantly to central nervous system neurons [21]. Heterozygous males were bred with wild-type C57BL/6 females (purchased from Jackson Laboratory). Offspring were ear punched and genotyped using polymerase chain reaction. Mice not expressing the transgene were used as wild-type controls. Mice were maintained in standard laboratory cages at $23^{\circ} \mathrm{C}$ under a 12 -h light/dark cycle (lights on at 08:00-20:00) with free access to water and food. All 
experimental procedures in this study were approved by the Committee on Animal Care of Shiga University of Medical Science.

\section{Magnetic resonance imaging}

We used a 7.0 T horizontal-bore MR scanner (Unity Inova; Agilent Technologies, Santa Clara, CA) [18, 20]. A home-built circular-type surface coil measuring $1.6 \mathrm{~cm}$ in diameter and tuned to both the ${ }^{1} \mathrm{H}$ and ${ }^{19} \mathrm{~F}$ frequencies ( $300 \mathrm{MHz}$ and $282 \mathrm{MHz}$, respectively) was used to collect the data. Compounds were dissolved at $10 \mathrm{mg} / \mathrm{ml}$ in saline containing $10 \%$ Cremophor EL or $10 \%$ Tween 80 before use. Mice, under anesthesia with sodium pentobarbital $(50 \mathrm{mg} / \mathrm{kg}$, i.p.; Dainippon Sumitomo Pharma, Osaka, Japan), were intravenously injected with compounds at a dose of $200 \mathrm{mg} / \mathrm{kg}$ via the tail vein over a 100 -min period by continuous infusion at a rate of $0.2 \mathrm{ml} / \mathrm{kg} / \mathrm{min}$. Immediately after the injection, the mice were placed in the MR scanner and general anesthesia was maintained with intermittent infusion of sodium pentobarbital through a polyethylene tube inserted intraperitoneally. Additional dosage of sodium pentobarbital for maintaining anesthesia was determined by monitoring respiratory rate. The animals were warmed with an air drier and rectal temperature was monitored throughout the experiments. We also measured MR in mice that were killed by an overdose of sodium pentobarbital $(200 \mathrm{mg} / \mathrm{kg}$, i.p.) at indicated time periods after injection of the compounds.

\section{${ }^{1}$ H gradient-echo magnetic resonance imaging}

${ }^{1} \mathrm{H}$ gradient-echo MR images of the mouse brain were obtained with $150-\mathrm{ms}$ repetition time (TR), 3 -ms echo time, $60^{\circ}$ flip angle, $1.5-\mathrm{mm}$ slice thickness, $24 \mathrm{~mm} \times 24 \mathrm{~mm}$ field of view, and $128 \times 128$ resolution.

\section{${ }^{19} \mathrm{~F}$ magnetic resonance measurement}

A nonlocalized ${ }^{19} \mathrm{~F}$ nuclear magnetic resonance (NMR) spectrum was obtained from the whole head using a single pulse sequence with 8192 data points, 40,000-Hz spectral width, 1 -s TR, and 600 acquisitions (for $10 \mathrm{~min}$ ).

Free induction decay data of ${ }^{19} \mathrm{~F}$ chemical shift imaging $\left({ }^{19} \mathrm{~F}\right.$ CSI $)$ were collected with a $40,000-\mathrm{Hz}$ spectral width, $24 \mathrm{~mm} \times 24 \mathrm{~mm}$ field of view in the horizontal and sagittal planes, 1-s TR, 200- $\mu$ s phase encoding time, and 68 acquisitions for each central
44 phase-encoding step out of $8 \times 8$ steps. For the residual 20 phase-encoding steps in the periphery of $\mathrm{k}$-space, zero data were used. The total acquisition time for one data set was $50 \mathrm{~min}$. A slice-selective pulse was not used, but slice selection was achieved by the sensitivity of the radio frequency (RF) coil in the case of the horizontal plane. Whole signals covered by the coil sensitivity were acquired. The raw data were processed by 3D-Fourier transformation with $40-\mathrm{Hz}$ line broadening and zero filling, and then finally converted to $32 \times 32$ spectral data sets. The ${ }^{19} \mathrm{~F}$ image was constructed by integrating the ${ }^{19} \mathrm{~F}$ signal intensities of compound peaks in individual pixels. We did not determine the flip angle of the excitation pulse for ${ }^{19} \mathrm{~F}$. The RF power was optimized to obtain the maximal ${ }^{19} \mathrm{~F}$ signal intensity with 1 -s TR using a compoundcontaining phantom and animals. The optimized RF power was used for both the ${ }^{19} \mathrm{~F}$ single pulse and ${ }^{19} \mathrm{~F}$ CSI sequences.

\section{Semi-quantitative analysis of ${ }^{19} F$ MR signal intensity in the brain region}

The signal intensity of ${ }^{19} \mathrm{~F}$ MR images with matrix size $256 \times 256$ pixels was quantified with image processing software (Image $\mathrm{J}$; National Institutes of Health, Bethesda, MD). Sixteen regions of interest (ROIs), with a square area of 64 pixels each, were placed evenly over the forebrain region of the ${ }^{19} \mathrm{~F} M R$ images. Then, mean density in the ROIs in the forebrain was measured. At the same time, mean background density was measured using 16 ROIs placed over a region where there was no tissue. Finally, the values of ${ }^{19} \mathrm{~F}$ MR signal intensity for the forebrain region were obtained by subtracting the background values from the forebrain values in each image.

\section{Immunohistochemistry}

Mice were sacrificed under deep anesthesia with sodium pentobarbital $(50 \mathrm{mg} / \mathrm{kg}$, i.p. $)$. The brain was removed quickly from each mouse, post-fixed in $4 \%$ paraformaldehyde for $24 \mathrm{~h}$ at $4{ }^{\circ} \mathrm{C}$, and then immersed in $0.1 \mathrm{M}$ phosphate buffer ( $\mathrm{pH} 7.4$ ) containing $15 \%$ sucrose and $0.1 \%$ sodium azide for at least 2 days for cryoprotection. We did not perfuse the brain before collection in the present study, unless otherwise specified. The brains were cut into $20-\mu \mathrm{m}$ sections in a cryostat. Free-floating sections were treated with $0.3 \%$ hydrogen peroxide in $0.1 \mathrm{M}$ phosphate-buffered saline (PBS) containing $0.3 \%$ Triton X-100 (PBS-T, pH 7.4) to eliminate endogenous peroxidase activity. After 
several washes, the sections were treated with $2 \%$ bovine serum albumin (BSA) in PBS-T for $30 \mathrm{~min}$ at room temperature to block non-specific protein binding. The sections were then incubated with rabbit polyclonal antibody against the $\mathrm{N}$-terminal of human $\mathrm{A} \beta$ (1:500; Immuno-Biological Laboratories, Takasaki, Japan) in PBS-T containing $0.2 \%$ BSA for $24 \mathrm{~h}$ at $4^{\circ} \mathrm{C}$, followed by biotinylated anti-rabbit $\operatorname{IgG}(1: 1,000$; Vector Laboratories, Burlingame, $\mathrm{CA}$ ) for $1 \mathrm{~h}$ at room temperature. The sections were then incubated with avidin-biotin-peroxidase complex (Vectastain ABC Elite kit, 1:3,000; Vector Laboratories) for $1 \mathrm{~h}$ at room temperature. All of the sections were washed several times with PBS-T between steps, and labeling was then revealed by 3,3'-diaminobenzidine (DAB; Dojindo Laboratories, Kumamoto, Japan), with nickel ammonium, which yielded a dark blue color. The sections were then mounted on glass slides and coverslipped with Entellan new (Merck Millipore, Billerica, MA).

For fluorescence microscopy, free-floating sections were treated with $2 \% \mathrm{BSA}$ in PBS-T for $30 \mathrm{~min}$ at room temperature to block non-specific protein binding. The sections were then incubated overnight at $4{ }^{\circ} \mathrm{C}$ with rabbit polyclonal antibody against the $\mathrm{N}$-terminal of human $\mathrm{A} \beta$ (1:500) in PBS-T containing $0.2 \%$ BSA, followed by Alexa Fluor 555-conjugated anti-rabbit IgG antibody (1:500; Invitrogen, Carlsbad, CA) in PBS-T for approximately $4 \mathrm{~h}$ at room temperature. All of the sections were washed several times with PBS$\mathrm{T}$ between steps. The sections were mounted on glass slides and coverslipped with Immu-Mount (Thermo, Pittsburgh, PA) for subsequent observation by fluorescence microscopy (BZ-8100; Keyence, Osaka, Japan) using a DAPI-BP filter (excitation filter $340-380 \mathrm{~nm}$; dichroic mirror $400 \mathrm{~nm}$; emission filter $435-485 \mathrm{~nm}$ ) for fluorescence from the compounds and a Texas Red filter (excitation filter 540-580 nm; dichroic mirror $595 \mathrm{~nm}$; emission filter $600-660 \mathrm{~nm}$ ) to visualize the anti-A $\beta$ antibody binding.

\section{Labeling with compound $3 b(m=6)$ in human $A D$ brain sections}

All experiments using human materials were approved by and performed in accordance with the guidelines of the Ethics Committees of Shiga University of Medical Science, and informed consent was obtained from the patients' guardians. Postmortem dissected brain blocks fixed with formalin were cut into $20-\mu \mathrm{m}$ sections. Compound $3 \mathrm{~b}(\mathrm{~m}=6)$ was dissolved at $2 \mathrm{mg} / \mathrm{ml}$ in dimethyl sulfoxide and the solution was then diluted to $50 \mu \mathrm{g} / \mathrm{ml}$ in PBS-T. The temporal lobe sections of $\mathrm{AD}$ brain were immersed in $50 \mu \mathrm{g} / \mathrm{ml}$ of compound $3 \mathrm{~b}(\mathrm{~m}=6)$ for $1 \mathrm{~h}$ at room temperature. The sections were then incubated with mouse monoclonal antibodies against $\mathrm{A} \beta$ (6E10; 1:1,000; Covance, Princeton, NJ) or tau phosphorylated at S202 and T205 (AT8; 1:2,000; Thermo) overnight at $4{ }^{\circ} \mathrm{C}$, followed by Alexa Fluor 647-conjugated anti-mouse IgG antibody (1:500; Invitrogen) for $4 \mathrm{~h}$ at room temperature. All antibodies were diluted in PBS-T, and sections were washed with PBS-T after each step. Stained sections were observed by fluorescence microscopy (BZ-8100).

\section{Statistical analysis}

Data are presented as mean \pm standard error of the mean (S.E.M.). The statistical significance between two groups was analyzed by the Mann-Whitney test (GraphPad Prism; GraphPad Software, La Jolla, CA).

\section{RESULTS}

\section{Comparison of ${ }^{19} F$ MR signal of compounds in the mouse brain}

First of all, it was important for us to determine the best length of PEG chain for linking the fluorinelabeled group with the core structure. To compare ${ }^{19} \mathrm{~F}$ MR signals between brains with and without amyloid deposition, AßPP/PS1 and wild-type mice aged 16 to 18 months were injected intravenously with the different compounds at a dose of $200 \mathrm{mg} / \mathrm{kg}$, and then euthanized $3 \mathrm{~h}$ after the end of the injection. Subsequently, ${ }^{19} \mathrm{~F}$ MRI was measured in the mouse head in the sagittal plane for $300 \mathrm{~min}$. We used one wild-type mouse and one A $\beta P P / P S 1$ mouse in each cohort.

Initially, we investigated the ${ }^{19} \mathrm{~F}$ MR signals of the compounds containing a single trifluoromethyl group in the molecule ( 3 fluorine atoms; type $b$ ): compounds $3 b(m=4), 3 b(m=5), 3 b(m=6), 5 b(m+n=7), 5 b$ $(m+n=8), 5 b(m+n=10)$, and $5 b(m+n=12)$, all of which have a trifluoroethoxy group with 5, 6, 7, 8, 9, 11 , and 13 ethylene glycol groups in the PEG chain, respectively. We generally used $10 \%$ Tween 80 to solubilize the compounds, but for compounds $3 \mathrm{~b}(\mathrm{~m}=4)$ and $3 \mathrm{~b}(\mathrm{~m}=5), 10 \%$ Cremophor EL was used, because these compounds did not dissolve in $10 \%$ Tween 80 .

Compounds $3 \mathrm{~b}(\mathrm{~m}=4)$ and $3 \mathrm{~b}(\mathrm{~m}=5)$ showed $\mathrm{a}$ moderate level of ${ }^{19} \mathrm{~F}$ MR signal in the forebrain and a strong signal in the cerebellum of A $\beta P P / P S 1$ mice, while no signal was detected in the forebrain of wild-type mice (Fig. 1). Compound $3 \mathrm{~b}(\mathrm{~m}=6)$ showed a stronger ${ }^{19} \mathrm{~F}$ MR signal in the entire brain 

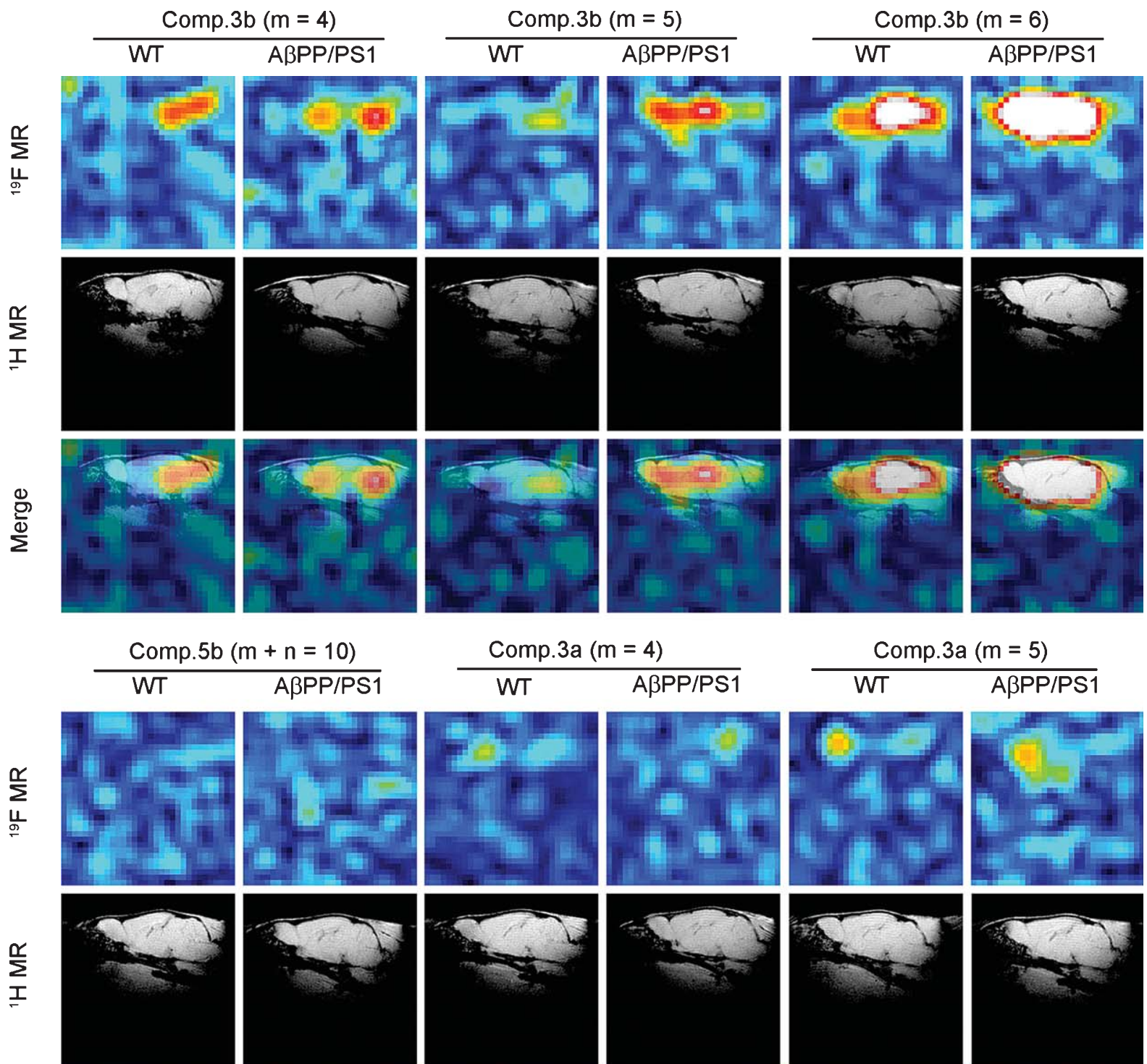

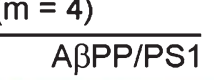
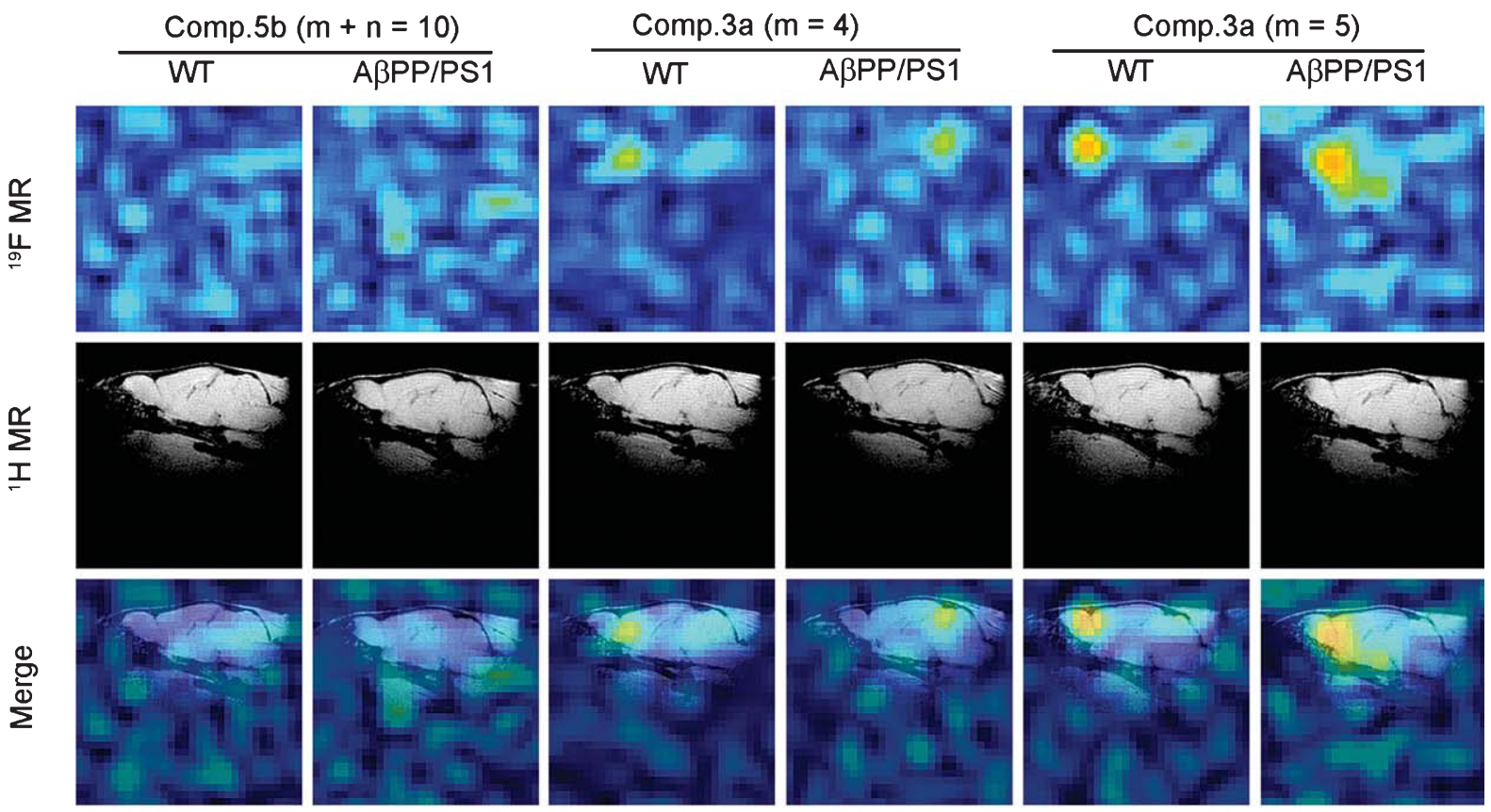

0

255

Fig. 1. Differences in fluorine-19 magnetic resonance ( $\left.{ }^{19} \mathrm{~F} \mathrm{MR}\right)$ signals in 16- to 18 -month-old wild-type (WT) and A $\beta P P s w e / P S 1 \mathrm{dE} 9$ doubletransgenic (AßPP/PS1) mice that were injected with probes prepared in the present study. Mice were euthanized $3 \mathrm{~h}$ after the injection of probes. Subsequently, ${ }^{19} \mathrm{~F}$ MR images were measured for $300 \mathrm{~min}$ in the sagittal plane.

of both A $\beta P P / P S 1$ and wild-type mice when it was dissolved in 10\% Cremophor EL (Fig. 1). On the other hand, when compound $3 \mathrm{~b}(\mathrm{~m}=6)$ was dissolved in $10 \%$ Tween 80 , a strong ${ }^{19} \mathrm{~F}$ MR signal was detected in the brain of $\mathrm{A} \beta \mathrm{PP} / \mathrm{PS} 1$ mice, whereas the ${ }^{19} \mathrm{~F}$ MR signal became weak in wild-type mice (Fig. 2A; $3 \mathrm{~h}$ ). ${ }^{19} \mathrm{~F}$ MR data in mice injected with compound $3 \mathrm{~b}(\mathrm{~m}=7)$ and compound $3 \mathrm{~b}(\mathrm{~m}=8)$ were 


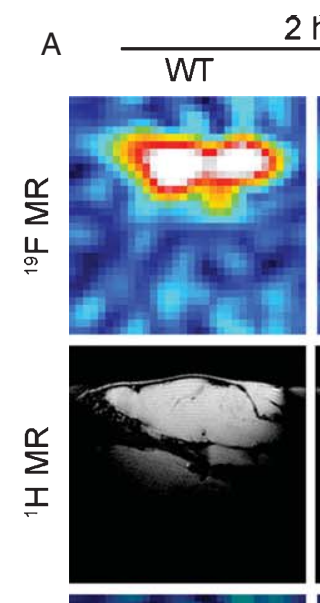

$2 \mathrm{~h}$

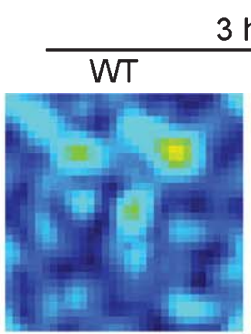

$3 \mathrm{~h}$
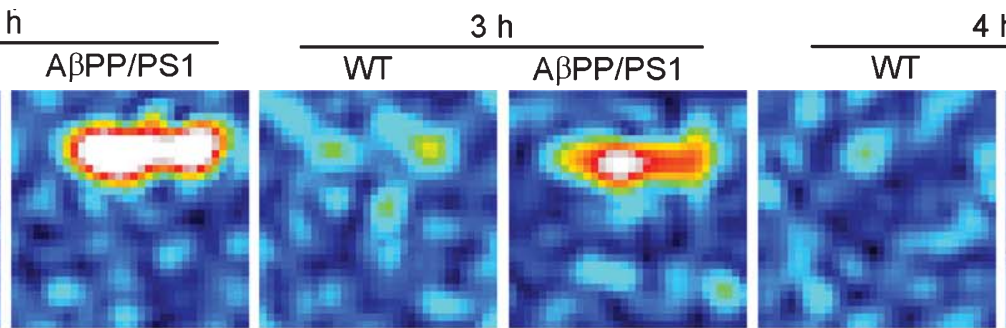

A $\mathrm{h}$
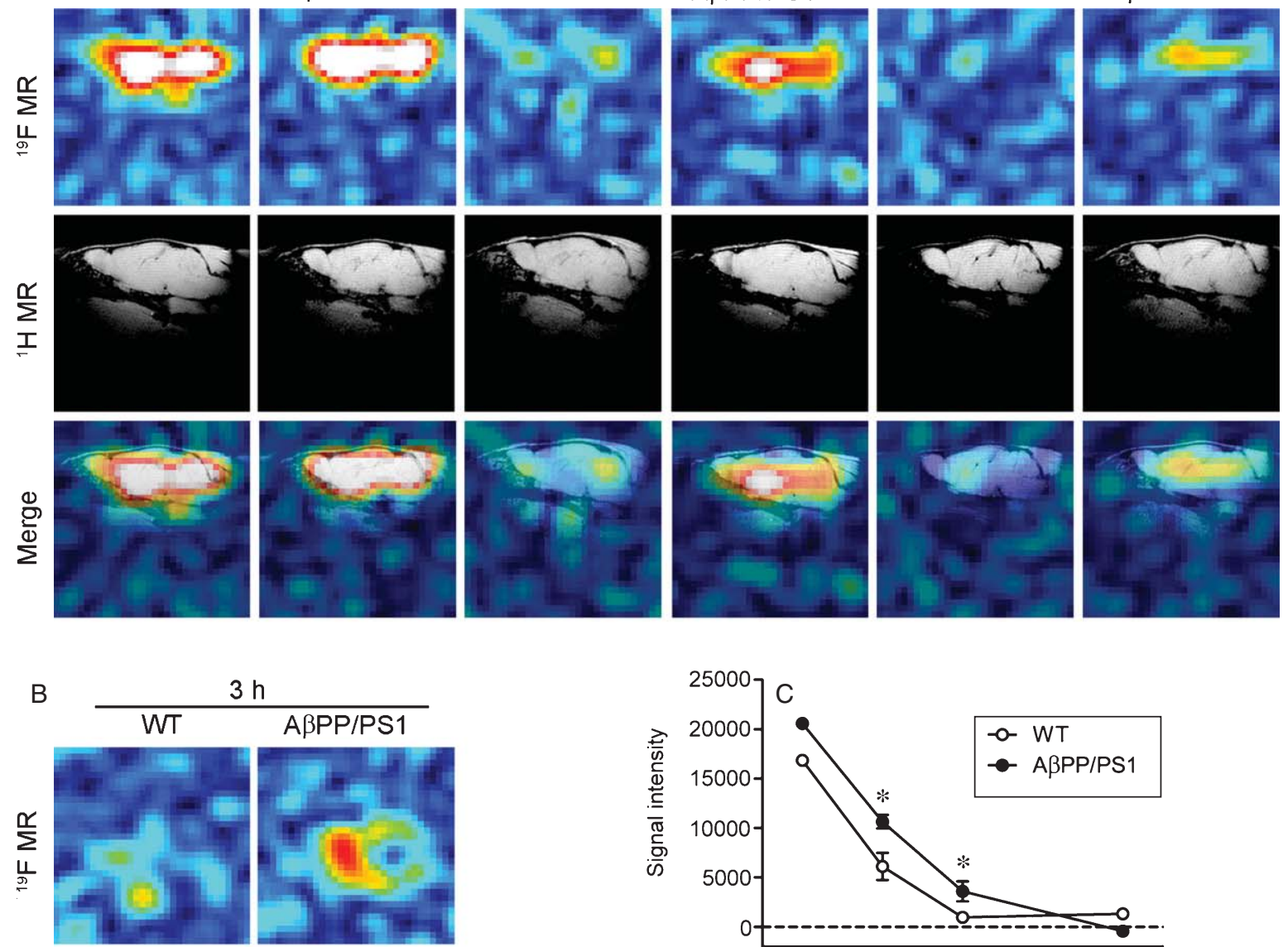

AßPP/PS1
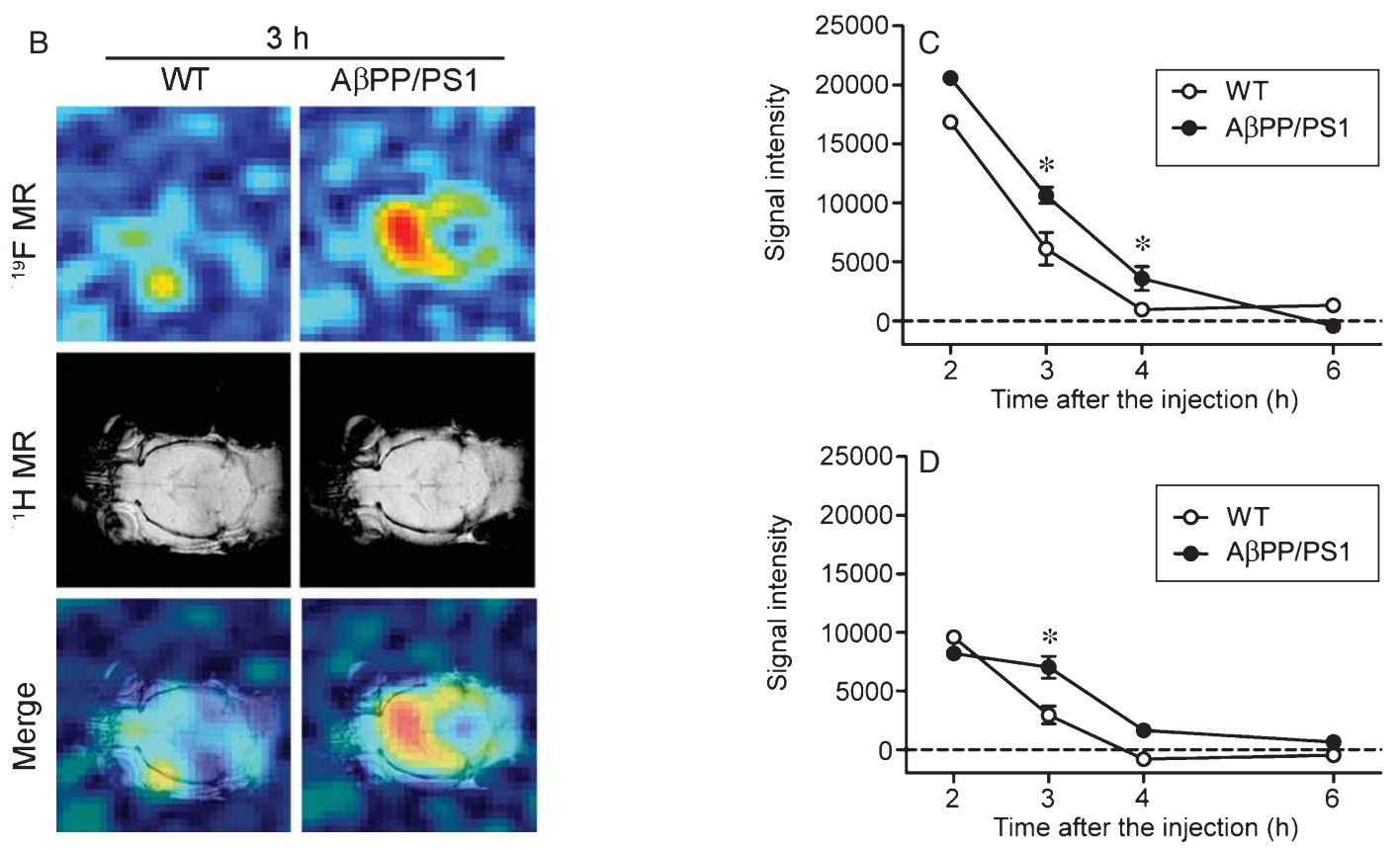

Fig. 2. Time course of changes in fluorine-19 magnetic resonance $\left({ }^{19} \mathrm{~F} \mathrm{MR}\right)$ signals in compound $3 \mathrm{~b}(\mathrm{~m}=6)$-injected 16 - to 18 -month-old wild-type (WT) and AßPPswe/PS1dE9 double-transgenic (AßPP/PS1) mice. Mice were euthanized 2, 3, 4, or 6h after the injection of probes. Subsequently, ${ }^{19} \mathrm{~F}$ MR images were measured for $300 \mathrm{~min}$ in the sagittal plane (A) and horizontal plane (B). Relative signal intensities in the brain in the sagittal plane (C) and the horizontal plane (D) were calculated and plotted. In the sagittal plane, n=1, 3, 3, and 1 WT mice and $\mathrm{n}=1,3,4$, and $1 \mathrm{~A} \beta \mathrm{PP} / \mathrm{PS} 1$ mice were imaged 2, 3, 4, and $6 \mathrm{~h}$ post-injection, respectively; in the horizontal plane, $\mathrm{n}=1,3,1$, and $1 \mathrm{WT}$ mice and $\mathrm{n}=1,3,2$, and $2 \mathrm{~A} \beta \mathrm{PP} / \mathrm{PS} 1$ mice were imaged 2, 3, 4, and $6 \mathrm{~h}$ post-injection, respectively. Data are presented as mean \pm standard error of the mean (S.E.M.). Significance (Mann-Whitney test): $* p<0.05$ versus WT.

not obtained, because 3 out of 3 mice died within $1 \mathrm{~h}$ post-injection. In mice injected with compound $5 \mathrm{~b}$ $(\mathrm{m}+\mathrm{n}=10)$ (Fig. 1) and compound $5 \mathrm{~b}(\mathrm{~m}+\mathrm{n}=12)$ (data not shown), the ${ }^{19} \mathrm{~F}$ MR signal was hardly detectable in the brain. In addition, ex vivo labeling with intravenously injected compound $5 b(m+n=10)$ 
and compound $5 \mathrm{~b}(\mathrm{~m}+\mathrm{n}=12)$ showed far weaker signals in A $\beta P P / P S 1$ mice, although intense spots were also detected in some of the plaques (Supplementary Figure 1). Taken together, these results suggest that the optimum number of ethylene glycol groups in the PEG chain to link with the fluorine-labeled group is seven.

Next, we tried to find out the best of the three types of trifluoromethyl groups ( $a, b$, or c). We measured the ${ }^{19} \mathrm{~F}$ MR signals of the $3^{\prime}, 5^{\prime}$-bis(trifluoromethyl) benzylamino derivatives (6 fluorine atoms; type a). No remarkable differences were detected between A $\beta P P / P S 1$ mice and wild-type mice for compounds $3 a(m=4)$ and $3 a(m=5)$. These compounds could be incorporated in adipose tissue in the orbit rather than the brain. We further tested the hexafluoroisopropoxy derivatives (6 fluorine atoms; type c). However, compounds $3 \mathrm{c}(\mathrm{m}=6)$ and $5 \mathrm{c}(\mathrm{m}+\mathrm{n}=8)$ could not be solubilized enough in the micelle of Tween 80 to be intravenously injected, so ${ }^{19} \mathrm{~F}$ MR data could not be obtained for these compounds.

We expected that the compounds containing two trifluoromethyl groups (6 fluorine atoms; type a and c) would give stronger ${ }^{19}$ F MR signals than those containing one trifluoromethyl group (3 fluorine atoms; type b) in the brain of A $\beta P P / P S 1$ mice. However, the above results suggested that increasing the number of trifluoromethyl groups would not necessarily be an effective way to make the ${ }^{19} \mathrm{~F}$ MR signal stronger. Based on these observations, we selected compound $3 b(m=6)$ (Scheme 1C) as a candidate ${ }^{19} \mathrm{~F}$ MRI probe for amyloid detection, and investigated it in the next part of the study. In addition, we chose $10 \%$ Tween 80 as the solubilizing agent for compound $3 \mathrm{~b}(\mathrm{~m}=6)$ because of the lower background level. The ${ }^{19} \mathrm{~F}$ MR signal results of the probes we synthesized in the present study are summarized in Table 2.

\section{Time course of changes in ${ }^{19} \mathrm{~F}$ MR signal for compound $3 b(m=6)$}

We next investigated the time course of changes in the ${ }^{19} \mathrm{~F}$ MR signals for compound $3 \mathrm{~b}(\mathrm{~m}=6)$ in 16 to 18-month-old A $\beta P P / P S 1$ and wild-type mice. The mice were euthanized at various time points $(2,3,4$, and $6 \mathrm{~h})$ after the injection of compound $3 \mathrm{~b}(\mathrm{~m}=6)$ dissolved in $10 \%$ Tween 80 . Subsequently, ${ }^{19}$ F MR signals were measured in the mouse head in the horizontal and sagittal planes for $300 \mathrm{~min}$. In the sagittal plane, $n=1,3,3$, and 1 wild-type mice and $n=1,3$, 4 , and $1 \mathrm{~A} \beta \mathrm{PP} / \mathrm{PS} 1$ mice were imaged 2, 3, 4, and $6 \mathrm{~h}$ post-injection, respectively; in the horizontal plane,
Table 2

Summary of the results of fluorine-19 magnetic resonance $\left({ }^{19} \mathrm{~F} \mathrm{MR}\right)$ imaging using the probes we synthesized in the present study

\begin{tabular}{lccc}
\hline $\begin{array}{l}\text { Length of PEG } \\
(\mathrm{m}, \mathrm{m}+\mathrm{n})\end{array}$ & \multicolumn{3}{c}{$\begin{array}{c}\text { Type of } \\
\text { trifluoromethyl group }\end{array}$} \\
\cline { 2 - 4 } & $3 \mathrm{a}, 5 \mathrm{a}$ & $3 \mathrm{~b}, 5 \mathrm{~b}$ & $3 \mathrm{c}, 5 \mathrm{c}$ \\
\hline 2 & & & \\
3 & $(1)$ & $(2)$ & \\
4 & $(1)$ & $(2)$ & \\
5 & & $(3)$ & \\
6 & & $(4)$ \\
7 & & $(4)$ \\
8 & & $(5)$ \\
9 & & & \\
10 & & $(5)$ \\
11 & & & \\
12 & & & \\
\hline
\end{tabular}

(1) No significant differences in the ${ }^{19} \mathrm{~F}$ MR signals between A $\beta P P$ swe/PS1dE9 double transgenic (AßPP/PS1) mice and wildtype mice were detected. (2) There were strong ${ }^{19} \mathrm{~F}$ MR signals in the brain of A $\beta P P / P S 1$ mice, compared with wild-type mice. (3) Intense ${ }^{19} \mathrm{~F}$ MR signal was detected in the brain of AßPP/PS1 mice which was more prominent than (2). (4) Mice died after the injection. (5) No ${ }^{19} \mathrm{~F}$ MR signal was detected in either A $\beta P P / P S 1$ mice or wild-type mice. (6) There was difficulty dissolving the compounds for intravenous injection.

$n=1,3,1$, and 1 wild-type mice and $n=1,3,2$, and 2 A $\beta P P / P S 1$ mice were imaged 2, 3, 4, and $6 \mathrm{~h}$ postinjection, respectively.

In the sagittal plane, strong ${ }^{19} \mathrm{~F}$ MR signals were detected in the brain of both A $\beta P P / P S 1$ mice and wildtype mice $2 \mathrm{~h}$ after injection (Fig. 2A). Although the ${ }^{19}$ F MR signals in the wild-type mice readily decreased in a time-dependent manner, sizeable ${ }^{19} \mathrm{~F}$ MR signals were still detected in the forebrain of A $\beta P P / P S 1$ mice 3 and $4 \mathrm{~h}$ after injection (Fig. 2A). In a semi-quantitative analysis of the ${ }^{19} \mathrm{~F}$ MR signal in the sagittal plane, ${ }^{19} \mathrm{~F}$ MR signal intensity was significantly higher in the forebrain of $\mathrm{A} \beta \mathrm{PP} / \mathrm{PS} 1$ mice 3 and $4 \mathrm{~h}$ post-injection, compared to wild-type mice ( $p<0.05$; Fig. $2 \mathrm{C}$ ). Significant ${ }^{19} \mathrm{FMR}$ signals were also detected in the forebrain of $\mathrm{A} \beta \mathrm{PP} / \mathrm{PS} 1 \mathrm{mice}$ in the horizontal plane $3 \mathrm{~h}$ postinjection ( $p<0.05$; Fig. 2B, D).

\section{${ }^{19} \mathrm{~F}$ MR measurement in living mice}

We next measured the ${ }^{19} \mathrm{~F}$ MR signals in living mice. A $\beta P P / P S 1$ mice $(n=3)$ and wild-type mice $(n=3)$, aged 16 to 20 months, were placed in the MR scanner immediately after the end of the injection of compound $3 \mathrm{~b}(\mathrm{~m}=6)$. Then, $\mathrm{a}{ }^{19} \mathrm{~F}$ NMR spectrum was obtained from the whole head using a single pulse sequence for $10 \mathrm{~min}$. Subsequently, ${ }^{19} \mathrm{~F}$ CSI data for construction of ${ }^{19} \mathrm{~F}$ MR images were collected from the head in the 

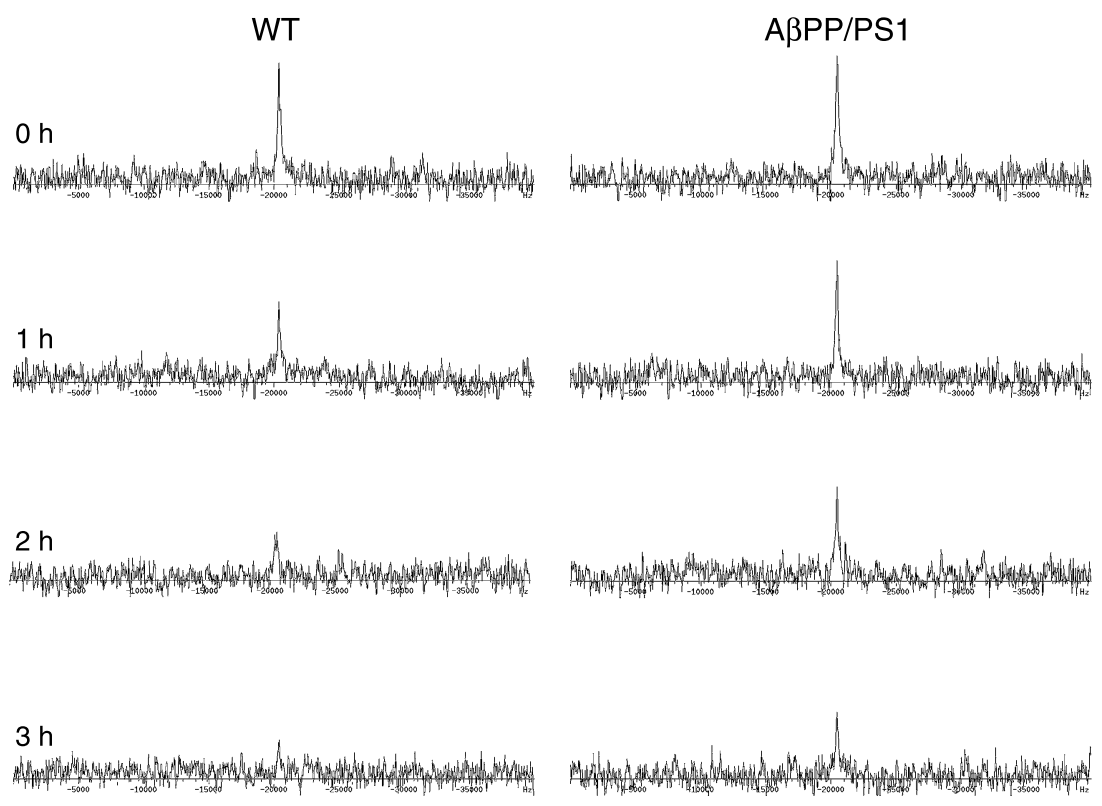

$4 \mathrm{~h}$ A4t

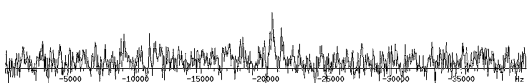

$8 \mathrm{~h}$

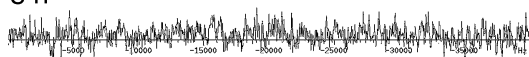

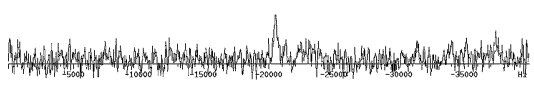

Fig. 3. Time course of changes in fluorine-19 nuclear magnetic resonance $\left({ }^{19} \mathrm{~F} \mathrm{NMR}\right)$ spectra in living 17 - to 20 -month-old wild-type (WT) and A $\beta$ PPswe/PS1dE9 double-transgenic (A $\beta P P / P S 1)$ mice that were injected with compound $3 \mathrm{~b}(\mathrm{~m}=6)$. Panels show representative non-localized ${ }^{19} \mathrm{~F}$ NMR spectra $0,1,2,3,4$, and $8 \mathrm{~h}$ after intravenous injection of compound $3 \mathrm{~b}(\mathrm{~m}=6)$.

sagittal plane for $50 \mathrm{~min}$. This set of MR measurements was repeated 7 times (a total of 8 sets).

In the ${ }^{19} \mathrm{~F} \mathrm{NMR}$ spectra, higher peaks were observed in A $\beta P P / P S 1$ mice $1 \mathrm{~h}$ after injection and later, although there was no difference between wild-type mice and A $\beta P P / P S 1$ mice immediately after the injection (Fig. 3). Then, although peaks in the wild-type mice were readily reduced by $3 \mathrm{~h}$ after injection, there remained substantial peaks in the A $\beta P P / P S 1$ mice even at $8 \mathrm{~h}$ after injection.

In the ${ }^{19} \mathrm{~F}$ MR images at the first measurement (10-60 min after injection of compound $3 b[\mathrm{~m}=6]$ ), strong ${ }^{19} \mathrm{~F}$ MR signals were observed in the brain of both wild-type mice and A $\beta P P / P S 1$ mice (Fig. 4A). However, the signals in the brain of wild-type mice readily reduced with time. In contrast, strong ${ }^{19} \mathrm{~F}$ MR signals were apparent in A $\beta P P / P S 1$ mice 1-2 and 2-3 h post-injection, and still remained $3-4 \mathrm{~h}$ post-injection, at which time the signal in wild-type mice had almost disappeared. We further compared ${ }^{19} \mathrm{~F}$ MR images that were constructed by adding the data collected from 3 to $8 \mathrm{~h}$ after injection. The ${ }^{19} \mathrm{~F}$ MR images clearly showed intense ${ }^{19} \mathrm{~F}$ MR signals accumulated in the brain of A $\beta P P / P S 1$ mice, while no signal was observed in wildtype mice (Fig. 4B). In addition, we measured ${ }^{19} \mathrm{~F} \mathrm{MR}$ images in A $\beta P P / P S 1$ mice at 14 to 15 months of age $(n=3)$; however, no significant ${ }^{19} \mathrm{~F}$ MR signals were apparent, compared with wild-type mice (Supplementary Figure 2).

\section{Distribution pattern of amyloid deposits and ex} vivo labeling with compound $3 b(m=6)$

After the MR measurements, we prepared brain sections to investigate the distribution pattern of amyloid deposits and ex vivo labeling of plaques with 
A
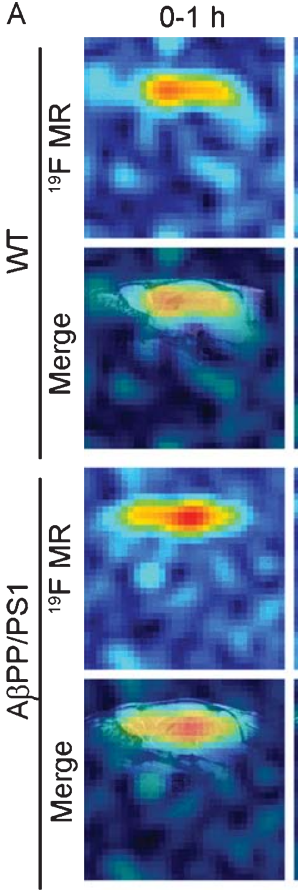

1-2 h
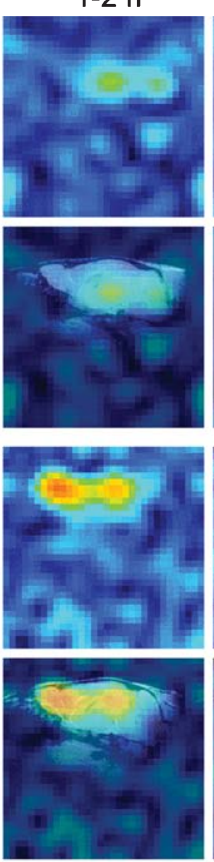

$2-3 h$
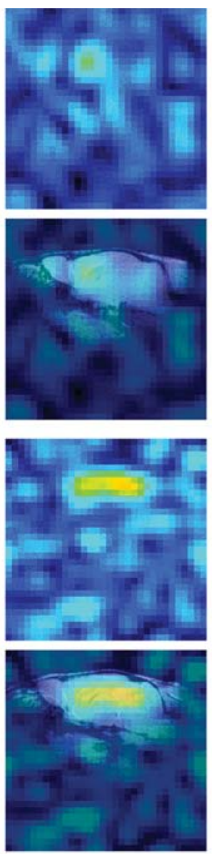

$3-4 h$
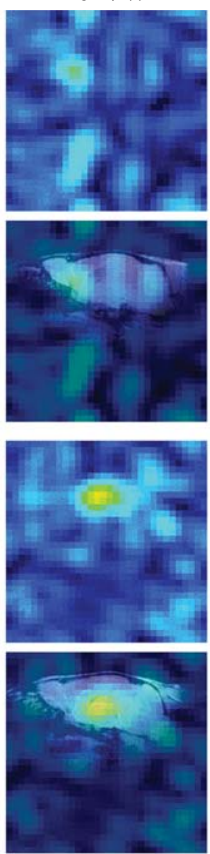

4-5 h
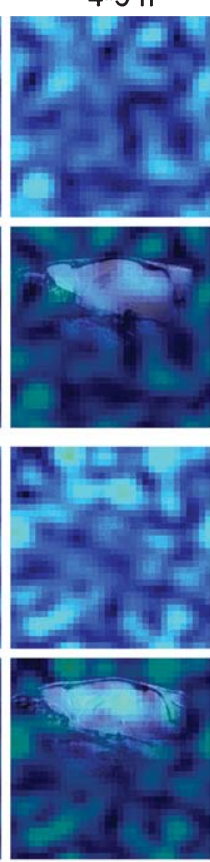

7-8 h
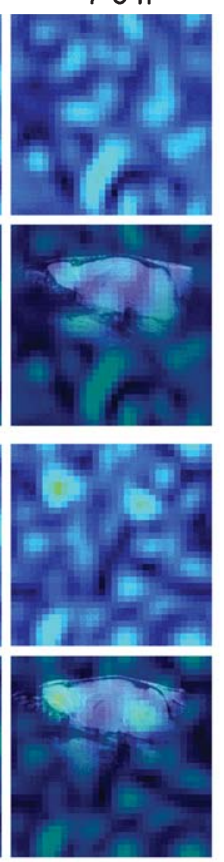
3-8 h
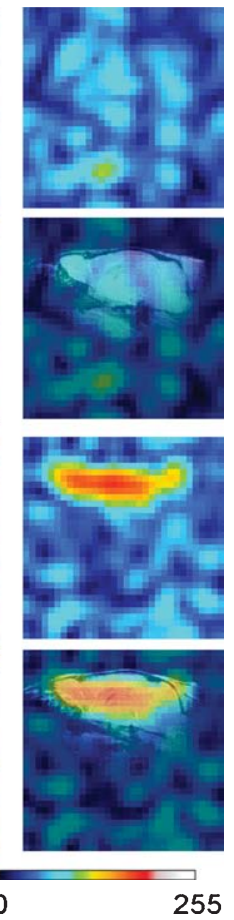

Fig. 4. Time course of changes in fluorine-19 magnetic resonance $\left({ }^{19} \mathrm{~F} \mathrm{MR}\right)$ signals in living 16- to 20-month-old wild-type (WT) and A $\beta P P s w e / P S 1 d E 9$ double transgenic (AßPP/PS1) mice that were injected with compound $3 \mathrm{~b}(\mathrm{~m}=6)$. A) Representative ${ }^{19} \mathrm{~F}$ MR images were obtained for $50 \mathrm{~min}$ at $0,1,2,3,4$, and $7 \mathrm{~h}$ after the intravenous injection of compound $3 \mathrm{~b}(\mathrm{~m}=6)$. B) Representative ${ }^{19} \mathrm{~F} \mathrm{MR}$ images were constructed by adding the data collected from $3 \mathrm{~h}$ to $8 \mathrm{~h}$ after the intravenous injection of compound $3 \mathrm{~b}(\mathrm{~m}=6)$.

intravenously injected compound $3 \mathrm{~b}(\mathrm{~m}=6)$. Fluorescence microscopy revealed massive punctate fluorescence for compound $3 \mathrm{~b}(\mathrm{~m}=6)$ in the cerebral cortex, hippocampus, and cerebellum in A $\beta P P / P S 1$ mice (Fig. 5). In addition, most of the fluorescence was colocalized with the $A \beta$ immunoreactivity. In contrast, no fluorescence for compound $3 b(m=6)$ or $A \beta$ immunoreactivity was apparent in wild-type mice.

\section{Labeling with compound $3 b(m=6)$ in human $A D$ brain sections}

Fluorescence microscopic analysis showed intense signal of compound $3 \mathrm{~b}(\mathrm{~m}=6)$ that was colocalized with consolidated $A \beta$ plaques in the temporal lobe (Fig. 6). In contrast, fluorescence signal of compound $3 \mathrm{~b}(\mathrm{~m}=6)$ was not detected in AT8-immunoreactive paired helical filament in human AD brain (Fig. 6).

\section{DISCUSSION}

In the present study, we compared ${ }^{19} \mathrm{~F}$ MR signals of fluorine-labeled compounds with PEG chains of dif- fering numbers of ethylene glycol groups in the mouse brain. The results suggested that compound $3 b(m=6)$, which bears a trifluoroethoxy group with seven ethylene glycol groups in the PEG chain, could be a useful ${ }^{19} \mathrm{~F}$ MRI probe for amyloid detection in the brain.

The probes we synthesized in the present study consisted of styrylbenzoxazole as a core structure linked to the fluorine-labeled group by differing lengths of PEG chain. Styrylbenzoxazole is known as an amyloidophilic group, and its derivatives, such as BF-168, can bind to amyloid plaques in the living mouse brain after intravenous injection [22, 23]. In addition, in vitro fluorescence staining of compound $3 b(m=6)$ in human AD brain sections showed high binding activity to senile plaques, and far less to neurofibrillary tangles. We used a PEG chain as a linker between the core structure and the fluorine-labeled group, and increasing the number of ethylene glycol groups in the PEG chain increases the hydrophilicity of the probes. In addition, using a PEG chain allows us to investigate the optimal distance between the core structure and the fluorinelabeled group, such that enough space is available to avoid inhibiting molecular mobility in the ${ }^{19} \mathrm{~F}$ atoms 

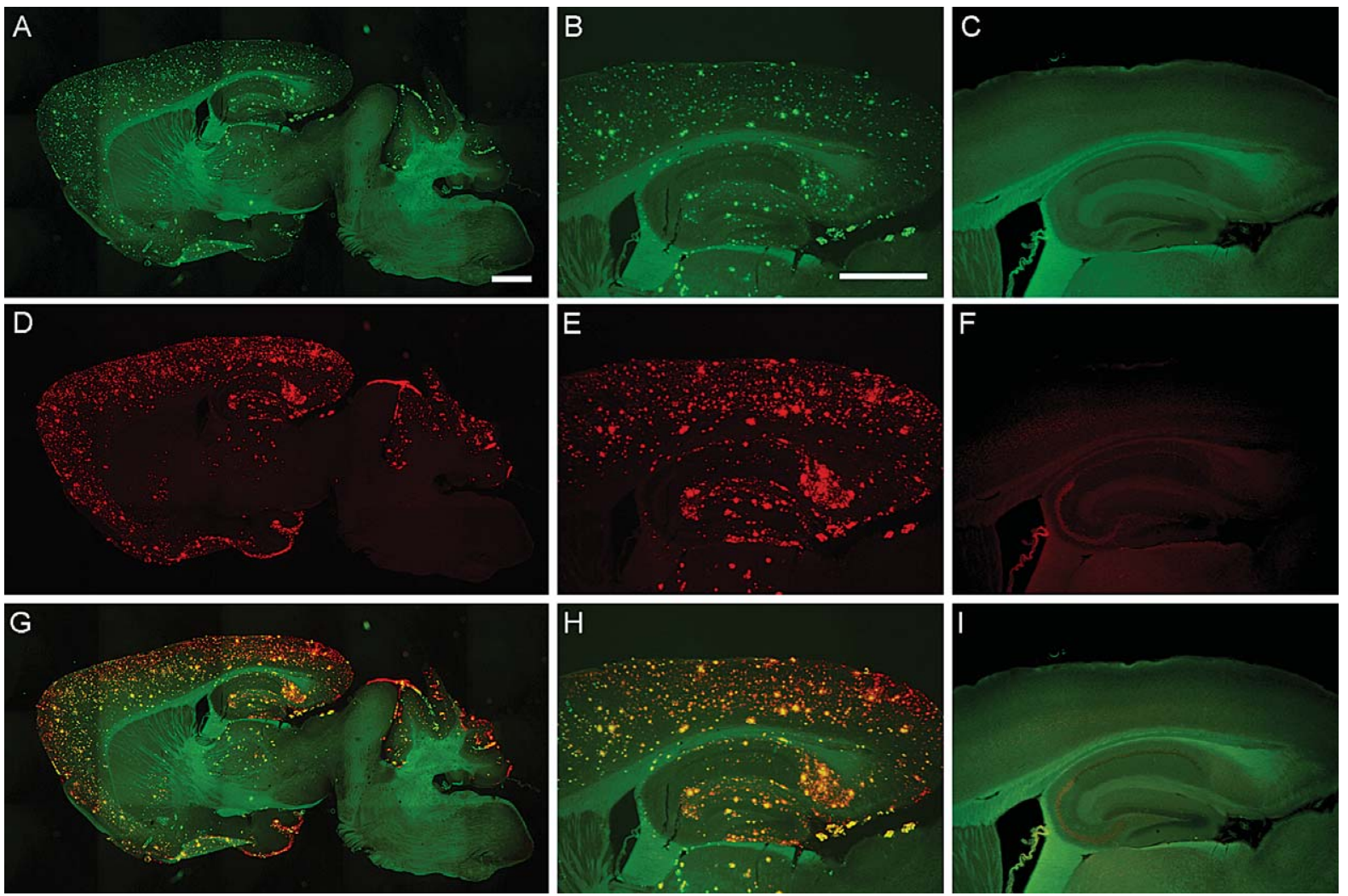

Fig. 5. Distribution pattern of amyloid deposits and ex vivo labeling with compound $3 \mathrm{~b}(\mathrm{~m}=6)$. Representative images show fluorescence microscopic analysis in sagittal brain sections of AßPPswe/PS1dE9 double-transgenic mice (A, B, D, E, G, H) and wild-type mice (C, F, I) that received an intravenous injection of compound $3 b(m=6)$. Fluorescence of compound $3 b(m=6)$ and immunoreactivity for amyloid- $\beta$ is shown as green $(\mathrm{A}-\mathrm{C})$ and red $(\mathrm{D}-\mathrm{F})$, respectively. Merged images (G-I). Scale bars are $1 \mathrm{~mm}(\mathrm{~A}, \mathrm{~B})$.

when they bind to amyloid plaques. Our results showed that compound $3 \mathrm{~b}(\mathrm{~m}=6)$, which has a trifluoroethoxy group with 7 ethylene glycol groups in the PEG chain, provided a remarkable ${ }^{19} \mathrm{~F}$ MR signal in AßPP/PS1 mouse brains, but not in wild-type mouse brains. The compounds bearing shorter PEG chains $(\mathrm{m}=2,3$ and 4) showed a weak level of ${ }^{19} \mathrm{~F}$ MR signal, suggesting a PEG chain of insufficient length to avoid the reduction in MR signal when bound to amyloid plaques in the brain. The compounds bearing eight and nine ethylene glycol groups in the PEG chain $(m+n=7$ and 8 ) proved fatal, although the cause of death was unclear. The compounds having longer PEG chains $(m+n=10$ and 12) showed no signals in the brain, probably because they are too large to penetrate the blood-brain barrier, which is supported by our findings of ex vivo labeling (Supplementary Figure 1). Based on these results, we concluded that seven ethylene glycol groups is the best length for the PEG chain to avoid the reduction in MR signal when the probe is bound to amyloid plaques.
This indicates that at least seven ethylene glycol groups are necessary for free mobility between the fluorinated group and the core structure that binds to the senile plaques in the brain.

In an in vitro study, increasing the number of fluorine atoms in the probe enabled us to detect higher NMR signal. However the hydrophobicity of the fluorine probe increases with the number of fluorine atoms, inducing an interaction with the membrane lipid in the brain $[6,20]$. Thus, increasing the number of fluorine atoms in the probe would be an inappropriate way to develop a highly sensitive probe. Furthermore, to achieve high-sensitivity detection, the optimal functional group containing the fluorine atoms should be selected carefully since that group would crucially affect the level of ${ }^{19} \mathrm{~F}$ MR signal in the brain in vivo. Taken together, these findings confirmed that compound $3 \mathrm{~b}(\mathrm{~m}=6)$, which has seven ethylene glycol groups in the PEG chain as a linker with the trifluoroethoxy group, would be the optimal probe for 

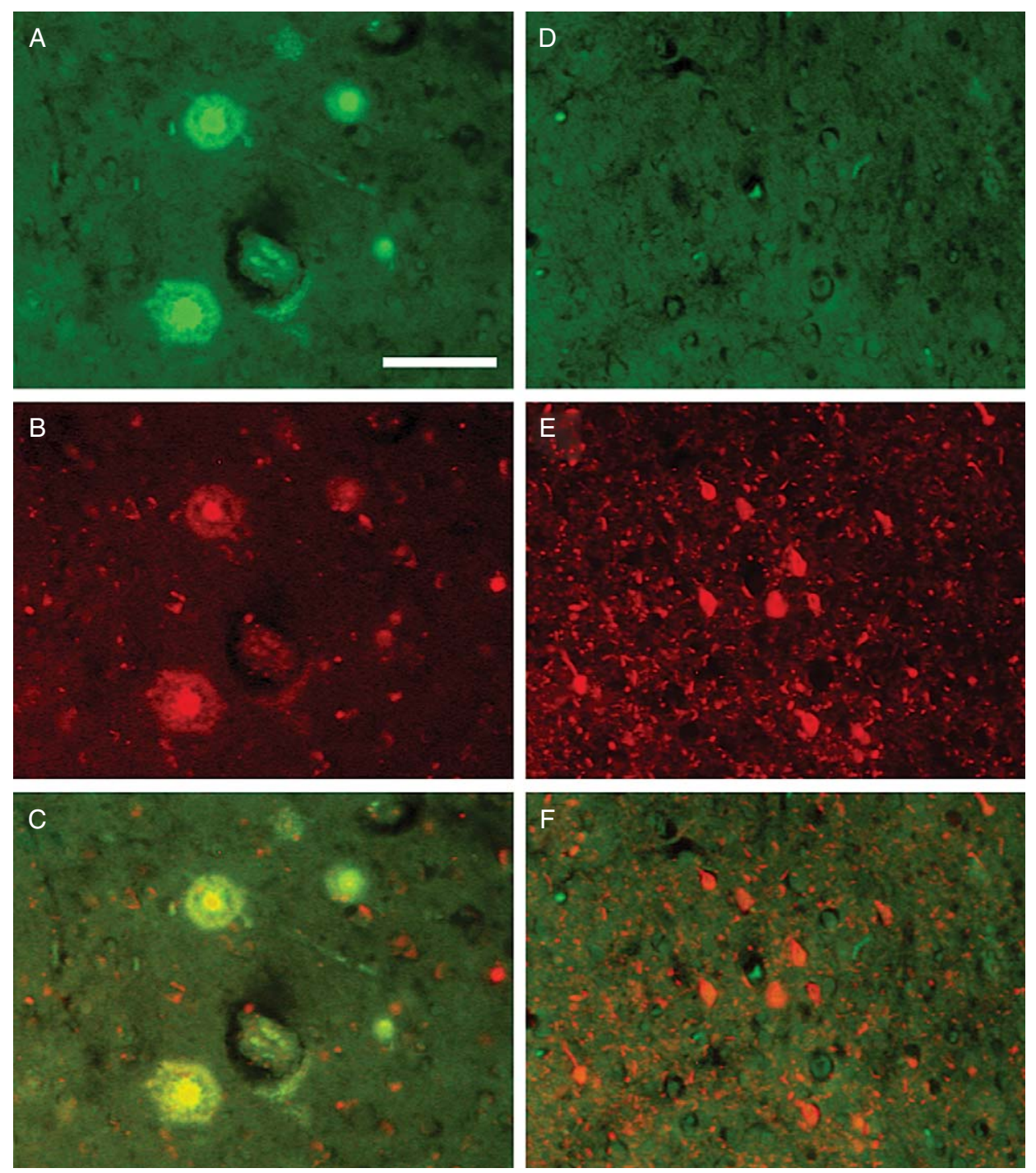

Fig. 6. Labeling with compound $3 \mathrm{~b}(\mathrm{~m}=6)$ in human Alzheimer's disease (AD) brain sections. Representative images show fluorescence microscopic analysis in the temporal lobe sections of AD brain. Fluorescence of compound $3 b(\mathrm{~m}=6)$ and immunoreactivity for amyloid- $\beta$ (6E10) and phosphorylated tau (AT8) is shown as green (A, D) and red (B, E), respectively. Merged images (C, F). Scale bar: $100 \mu \mathrm{m}$ (A).

maintaining a robust MR signal when bound to amyloid plaques. This finding is supported by the result that a strong ${ }^{19} \mathrm{~F}$ MR signal was detected in the brain of compound $3 \mathrm{~b}(\mathrm{~m}=6)$-injected A $\beta P P / P S 1$ mice that were perfused with saline $3 \mathrm{~h}$ post-injection (Supplementary Figure 3).

In the present study we used two surfactants, Tween 80 and Cremophor EL, to dissolve the probes for intravenous injection. The results showed intense ${ }^{19} \mathrm{~F}$ MR signals in both the A $\beta P P / P S 1$ and wild-type mouse brains with compound $3 \mathrm{~b}(\mathrm{~m}=6)$ dissolved in $10 \%$ Cremophor EL. In contrast, compound $3 b$ $(\mathrm{m}=6)$ dissolved in $10 \%$ Tween 80 showed strong ${ }^{19} \mathrm{~F}$ MR signals only in A $\beta P P / P S 1$ mice, and little signal in wild-type mice, indicating a significant difference between A $\beta P P / P S 1$ mice and wild-type mice. Therefore, we used $10 \%$ Tween 80 as a solubilizing agent for compound $3 \mathrm{~b}(\mathrm{~m}=6)$. In our preliminary study, the decreasing rate of ${ }^{19} \mathrm{~F}$ MR signal from the head became slower when the compounds were injected in $10 \%$ Cremophor EL. Thus, the solubilizing agent is another key factor, because it appears to change the distribution or metabolism of the probe, and thus affects ${ }^{19} \mathrm{~F}$ MR signals. 
We detected a remarkable ${ }^{19} \mathrm{~F}$ MR signal in the brain of living A $\beta P P / P S 1$ mice over 17 months of age after injection of compound $3 \mathrm{~b}(\mathrm{~m}=6)$. The brain region in which ${ }^{19} \mathrm{~F}$ MR signals were detected was in accordance with the distribution pattern of amyloid deposits in the brain of A $\beta P P / P S 1$ mice. In contrast, the ${ }^{19} \mathrm{~F}$ MR signal was slightly, but not obviously, apparent in the brain of living 14-month-old A $\beta P P / P S 1$ mice that had already developed moderate amyloid deposits in the brain (Supplementary Figure 4). Immunohistochemical analysis of A $\beta P P / P S 1$ mice at 20 months of age showed high levels of amyloid deposition in the brain, compared with that at 14 months of age (Supplementary Figure 4). Thus, the level of ${ }^{19} \mathrm{~F}$ MR signal detected by our method would depend on the level of amyloid deposition in the brain, and sensitivity would need to be improved to detect amyloid deposition in younger $\mathrm{A} \beta \mathrm{PP} / \mathrm{PS} 1$ mice.

We did not determine the bioavailability and toxicity of the compounds in the present study. A study by Okamura et al. showed that the ${ }^{18} \mathrm{~F}$-radiolabeled styrylbenzoxazole derivative, BF-168, displayed ideal kinetic properties, including abundant initial brain uptake $3.9 \%$ of the injected dose per gram at 2 min after injection) and a short clearance half-life (24.7 $\mathrm{min}$ ) in normal mouse brain, although some persistence of BF-168 or its metabolites remained in the plasma over $1 \mathrm{~h}$ after the injection [23]. Thus, while detailed investigations are still needed, we believe that our styrylbenzoxazole compounds also show good bioavailability to image amyloid deposition in the brain. On the other hand, the toxicity of the compounds has not been elucidated. Compounds $5 \mathrm{~b}(\mathrm{~m}+\mathrm{n}=7$ and 8 ) bearing eight and nine ethylene glycol groups in the PEG chain, respectively, proved fatal, implying that the compounds used in the present study have potential toxicity. However we found no obvious sign of toxicity in the central nervous system or peripheral organs in mice following injections of compound $3 \mathrm{~b}(\mathrm{~m}=6)$ and others, except for compounds $5 b(m+n=7$ and 8 ). Therefore although further study is still needed, we consider that compound $3 \mathrm{~b}(\mathrm{~m}=6)$ shows very low toxicity.

Currently, PET is used as a powerful imaging modality to detect amyloid deposition. PET has great advantages including excellent sensitivity, the very low doses required, and high quantitative ability, compared to other imaging modalities. However, it suffers from some drawbacks, including limited spatial resolution, the need to manipulate radioactive compounds, and the high cost and the narrow availability of radioisotopes for PET probes as well as the low availability of
PET scanners for preclinical studies in animals. Thus, alternative methods based on other imaging modalities, such as MRI, are currently being developed to detect amyloid plaques. MRI would offer several advantages over PET because MRI provides better spatial resolution, is more widely available, is less costly, and lacks radiation exposure as compared to PET.

Recent studies demonstrated that individual amyloid plaques in AD model mice are detectable as hypointense spots in T2- and T2*-weighted ${ }^{1} \mathrm{H}$ MR images from a high field MR scanner [7, 8, 10, 11]. In this case, it is likely that the hypointense spots based on the reduction in $\mathrm{T} 2$ are induced by accumulation of metals such as iron in the amyloid plaques and/or by other factors such as the dense structure of the plaques. However, the number of spots visualized by intrinsic MRI is far less than the number of plaques seen in histological analysis. In addition, this method is not specific for amyloid plaques because it also detects other iron-containing structures such as remnants of old hemorrhages and calcification. On the other hand, several contrast agents are being developed to enhance the detectability of plaques in ${ }^{1} \mathrm{H}$ MRI, such as Gd- or UPSIO-labeled amyloid binding agent [13, 17]. This imaging method is able to detect more amyloid plaques with increasing signal-to-noise ratio and contrast-to-noise ratio. However, use of a technique to induce transient blood-brain barrier opening to deliver the contrast agent into the brain is needed to visualize amyloid plaques in MRI, since these contrast agents do not readily cross the blood-brain barrier. Therefore, in this context and according to the advantages mentioned in the Introduction, our ${ }^{19} \mathrm{~F}$ MRI technique could be a potential alternative imaging technique for evaluating amyloid deposition. For clinical applications, we need to modify the methodology to overcome several problems, such as the high dose required for imaging and the low sensitivity and resolution.

In the present study, we investigated the preferred features of a ${ }^{19} \mathrm{~F}$ MRI probe for amyloid detection in the brain, and found compound $3 \mathrm{~b}(\mathrm{~m}=6)$ to be the best candidate. This compound has seven ethylene glycol groups in the PEG chain as a linker between the core structure and the trifluoroethoxy group. Compound $3 \mathrm{~b}(\mathrm{~m}=6)$ showed strong ${ }^{19} \mathrm{~F}$ MR signals in the brain where massive amyloid deposition was detected, suggesting that the probes could generate a high level of ${ }^{19} \mathrm{~F}$ MR signal when bound to amyloid plaques in the brain. Thus, this study has identified the optimum length of PEG chain and appropriate fluorine-labeled group for a probe to generate a strong MR signal for amyloid imaging with ${ }^{19} \mathrm{~F}$ MRI. 


\section{ACKNOWLEDGMENTS}

The authors thank Ms. Takako Sasamura for her excellent technical assistance. This study was supported by Grant-in-Aids for Scientific Research (B) (JSPS KAKENHI Grant Number 22300153) (I.T.) and for Young Scientists (B) (25750159) (D.Y.) from the Japan Society for the Promotion of Science (JSPS), and a Grant-in-Aid for Scientific Research on Innovative Areas ("Brain Environment") (MEXT KAKENHI Grant Number 24111522) (I.T.) from the Ministry of Education, Science, Sports and Culture of Japan (MEXT).

Authors' disclosures available online (http://www.jalz.com/disclosures/view.php?id=1976).

\section{SUPPLEMENTARY MATERIAL}

Supplementary material is available in the electronic version of this article: http://dx.doi.org/10.3233/JAD131025 .

\section{REFERENCES}

[1] Citron M (2010) Alzheimer's disease: Strategies for disease modification. Nat Rev Drug Discov 9, 387-398.

[2] Querfurth HW, LaFerla FM (2010) Alzheimer's disease. N Engl J Med 362, 329-344.

[3] Hardy J, Selkoe DJ (2002) The amyloid hypothesis of Alzheimer's disease: Progress and problems on the road to therapeutics. Science 297, 353-356.

[4] Jack CR Jr, Knopman DS, Jagust WJ, Shaw LM, Aisen PS, Weiner MW, Petersen RC, Trojanowski JQ (2010) Hypothetical model of dynamic biomarkers of the Alzheimer's pathological cascade. Lancet Neurol 9, 119-128.

[5] Sperling RA, Aisen PS, Beckett LA, Bennett DA, Craft S, Fagan AM, Iwatsubo T, Jack CR Jr, Kaye J, Montine TJ, Park DC, Reiman EM, Rowe CC, Siemers E, Stern Y, Yaffe K, Carrillo MC, Thies B, Morrison-Bogorad M, Wagster MV, Phelps CH (2011) Toward defining the preclinical stages of Alzheimer's disease: Recommendations from the National Institute on Aging-Alzheimer's Association workgroups on diagnostic guidelines for Alzheimer's disease. Alzheimers Dement 7, 280-292.

[6] Amatsubo T, Yanagisawa D, Morikawa S, Taguchi H, Tooyama I (2010) Amyloid imaging using high-field magnetic resonance. Magn Reson Med Sci 9, 95-99.

[7] Benveniste H, Einstein G, Kim KR, Hulette C, Johnson GA (1999) Detection of neuritic plaques in Alzheimer's disease by magnetic resonance microscopy. Proc Natl Acad Sci U S A 96, 14079-14084.

[8] Chamberlain R, Reyes D, Curran GL, Marjanska M, Wengenack TM, Poduslo JF, Garwood M, Jack CR, Jr. (2009) Comparison of amyloid plaque contrast generated by $\mathrm{T} 2$-weighted, $\mathrm{T} 2 *$-weighted, and susceptibility-weighted imaging methods in transgenic mouse models of Alzheimer's disease. Magn Reson Med 61, 1158-1164.
[9] Higuchi M, Iwata N, Matsuba Y, Sato K, Sasamoto K, Saido TC (2005) ${ }^{19} \mathrm{~F}$ and ${ }^{1} \mathrm{H}$ MRI detection of amyloid beta plaques in vivo. Nat Neurosci 8, 527-533.

[10] Jack CR Jr, Garwood M, Wengenack TM, Borowski B, Curran GL, Lin J, Adriany G, Gröhn OH, Grimm R, Poduslo JF (2004) In vivo visualization of Alzheimer's amyloid plaques by magnetic resonance imaging in transgenic mice without a contrast agent. Magn Reson Med 52, 1263-1271.

[11] Jack CR Jr, Wengenack TM, Reyes DA, Garwood M, Curran GL, Borowski BJ, Lin J, Preboske GM, Holasek SS, Adriany $\mathrm{G}$, Poduslo JF (2005) In vivo magnetic resonance microimaging of individual amyloid plaques in Alzheimer's transgenic mice. J Neurosci 25, 10041-10048.

[12] Petiet A, Santin M, Bertrand A, Wiggins CJ, Petit F, Houitte D, Hantraye P, Benavides J, Debeir T, Rooney T, Dhenain M (2012) Gadolinium-staining reveals amyloid plaques in the brain of Alzheimer's transgenic mice. Neurobiol Aging 33, 1533-1544.

[13] Poduslo JF, Wengenack TM, Curran GL, Wisniewski T, Sigurdsson EM, Macura SI, Borowski BJ, Jack CR Jr (2002) Molecular targeting of Alzheimer's amyloid plaques for contrast-enhanced magnetic resonance imaging. Neurobiol Dis 11, 315-329.

[14] Sigurdsson EM, Wadghiri YZ, Mosconi L, Blind JA, Knudsen E, Asuni A, Scholtzova H, Tsui WH, Li Y, Sadowski M, Turnbull DH, de Leon MJ, Wisniewski T (2008) A nontoxic ligand for voxel-based MRI analysis of plaques in AD transgenic mice. Neurobiol Aging 29, 836-847.

[15] Wadghiri YZ, Sigurdsson EM, Sadowski M, Elliott JI, Li Y, Scholtzova H, Tang CY, Aguinaldo G, Pappolla M, Duff K, Wisniewski T, Turnbull DH (2003) Detection of Alzheimer's amyloid in transgenic mice using magnetic resonance microimaging. Magn Reson Med 50, 293-302.

[16] Wengenack TM, Reyes DA, Curran GL, Borowski BJ, Lin J, Preboske GM, Holasek SS, Gilles EJ, Chamberlain R, Marjanska M, Jack CR Jr, Garwood M, Poduslo JF (2011) Regional differences in MRI detection of amyloid plaques in AD transgenic mouse brain. Neuroimage 54, 113-122.

[17] Yang J, Wadghiri YZ, Hoang DM, Tsui W, Sun Y, Chung E, Li Y, Wang A, de Leon M, Wisniewski T (2011) Detection of amyloid plaques targeted by USPIO-A $\beta$ 1-42 in Alzheimer's disease transgenic mice using magnetic resonance microimaging. Neuroimage 55, 1600-1609.

[18] Amatsubo T, Morikawa S, Inubushi T, Urushitani M, Taguchi $\mathrm{H}$, Shirai N, Hirao K, Kato M, Morino K, Kimura H, Nakano I, Yoshida C, Okada T, Sano M, Tooyama I (2009) Trifluoromethoxy-benzylated ligands improve amyloid detection in the brain using ${ }^{19} \mathrm{~F}$ magnetic resonance imaging. Neurosci Res 63, 76-81.

[19] Yanagisawa D, Shirai N, Amatsubo T, Taguchi H, Hirao $\mathrm{K}$, Urushitani M, Morikawa S, Inubushi T, Kato M, Kato F, Morino K, Kimura H, Nakano I, Yoshida C, Okada T, Sano M, Wada Y, Wada K, Yamamoto A, Tooyama I (2010) Relationship between the tautomeric structures of curcumin derivatives and their Abeta-binding activities in the context of therapies for Alzheimer's disease. Biomaterials 31, 41794185.

[20] Yanagisawa D, Amatsubo T, Morikawa S, Taguchi H, Urushitani M, Shirai N, Hirao K, Shiino A, Inubushi T, Tooyama I (2011) In vivo detection of amyloid $\beta$ deposition using ${ }^{19} \mathrm{~F}$ magnetic resonance imaging with a ${ }^{19} \mathrm{~F}$-containing curcumin derivative in a mouse model of Alzheimer's disease. Neuroscience 184, 120-127.

[21] Jankowsky JL, Fadale DJ, Anderson J, Xu GM, Gonzales V, Jenkins NA, Copeland NG, Lee MK, Younkin LH, Wagner 
SL, Younkin SG, Borchelt DR (2004) Mutant presenilins specifically elevate the levels of the 42 residue beta-amyloid peptide in vivo: Evidence for augmentation of a 42-specific gamma secretase. Hum Mol Genet 13, 159-170.

[22] Kudo Y, Okamura N, Furumoto S, Tashiro M, Furukawa $\mathrm{K}$, Maruyama $\mathrm{M}$, Itoh $\mathrm{M}$, Iwata $\mathrm{R}$, Yanai $\mathrm{K}$, Arai H (2007) 2-(2-[2-Dimethylaminothiazol-5-yl]ethenyl)-6-(2[fluoro]ethoxy)benzoxazole: A novel PET agent for in vivo detection of dense amyloid plaques in Alzheimer's disease patients. J Nucl Med 48, 553-561.

[23] Okamura N, Suemoto T, Shimadzu H, Suzuki M, Shiomitsu T, Akatsu H, Yamamoto T, Staufenbiel M, Yanai K, Arai H, Sasaki H, Kudo Y, Sawada T (2004) Styrylbenzoxazole derivatives for in vivo imaging of amyloid plaques in the brain. J Neurosci 24, 2535-2541. 